\title{
Application of loT using nodeMCU ESP8266 on the Syringe Pump Device to Increase Patient Safety
}

\author{
Annisa Gallela Anjani ${ }^{1}$, Presillia Grisviani Sunarto ${ }^{1}$, Royan Royan ${ }^{1}$, Kusnanto Mukti \\ Wibowo ${ }^{1}$, Gema Romadhona ${ }^{1}$, Rum Sapundani ${ }^{1}$, Arif Mulyanto ${ }^{2}$, Iwan Setiawan ${ }^{3}$, and \\ Jumrianto ${ }^{4}$, N. Prasath ${ }^{5}$ \\ ${ }^{1}$ Department of Electromedical Engineering, Universitas Muhammadiyah Purwokerto, Indonesia \\ ${ }^{2}$ Department of Medical Laboratory Technology, Universitas Muhammadiyah Purwokerto, Purwokerto, Indonesia \\ ${ }^{3}$ Department of Electrical Engineering, Diponegoro University, Indonesia \\ ${ }^{3}$ Faculty of Science and Technology, IVET University, Semarang, Indonesia \\ ${ }^{4}$ Department of Networking and Communications, School of Computing, SRM Institute of Science and Technology, India \\ Corresponding author: Royan, R. (e-mail: royan@ump.ac.id).
}

\begin{abstract}
Nowadays, health care has turned out to be more technology-oriented. Today's technology is demanded to be practical and easy to use. The number of mobile devices based on the Android operating system has increased significantly based on data. The open-source nature of android helps in programming applications easily according to user requirements. A syringe pump is a medical device that functions to enter the medicinal fluid into the patient's body at a specific dose and time automatically in $\mathrm{mL} /$ hour. The syringe pump is generally equipped with an alarm. Alarms have a vital function to provide information to nurses or doctors on duty. Medical officers cannot hear alarms outside the patient monitoring room. This paper aims to design a syringe pump equipped with a NodeMCU8266 WiFi module to provide notifications via a smartphone so that nurses or doctors can know the alarm even though they are outside the patient monitoring room. So, this is expected can improve patient safety. In addition, this paper also aims to verify the size of the syringe against the drug flow rate. Based on the test results, the syringe pump can control the drug flow rate with a sensor accuracy of 0.0217 and an error rate of $0.6 \%$ at a target volume of $5 \mathrm{~mL}$. The syringe pump can also send alarm notifications to smartphones in real-time.
\end{abstract}

INDEX TERMS IoT, Syringe pump, safety patient, medical device, NodeMCU ESP8266.

\section{INTRODUCTION}

Technological advances can encourage innovations by applying the concept of IoT (Internet of Things), a concept that aims to broaden the benefits of continuous internet connectivity such as data sharing, remote control, and including objects in the real world. For example, food, electronics, any equipment, including living things, are connected to local and global networks through embedded sensors and are always active. Several studies related to IoT applications include, in the agricultural sector [1]-[4] Smart home [5]-[7], smart fish farm [8]-[10].
The IoT concept is also widely applied to medical equipment, such as research conducted by a researcher from the Department of Electromedical Engineering Poltekkes Ministry of Health, Surabaya Agatha Putri Junior, and colleagues [11]. Their research offers IoT applications for Vital signs monitoring patients who need treatment intensively, and their vital condition can be monitored remotely. IoT is also applied to the Patient Monitoring System [12]. Heart disease monitoring [13], Remote Health Monitoring System a[14], and similar studies were carried out by Shivam Gupta et al. [15]. 
A syringe pump is a medical device used to provide liquid medicine or nutrition into the patient's body in a certain amount and time regularly and automatically [16]-[18]. Syringe pumps are designed to push liquids [19], generally driven by a stepper motor [20], [21], or direct current motor [22], which is controlled by a microcontroller. Syringe pumps are applied in various fields such as the healthcare and pharmaceutical industries [23]. But unfortunately, the current syringe pump still has several weaknesses, including the absence of notification if the liquid inside is about to run out or experience blockage. These problems will only be known if observed directly at the location.

In this paper, we offer a syringe pump design equipped with a NodeMCU8266 WiFi module to provide notifications via a smartphone so that nurses or doctors can know the alarm even though they are outside the patient monitoring room. So this is expected can improve patient safety. The syringe pump is equipped with a Near Empty Alarm to provide information that the drug or nutrient liquid will be running out soon [24]. Alarms have a vital role in providing information to nurses or doctors.

\section{METHODOLOGY}

\section{A. EXPERIMENTAL SETUP}

The experiment was conducted by using a $50 \mathrm{~mL}$ syringe with a drug flow rate of $100 \mathrm{~mL} / \mathrm{h}$. At the same time, the target volumes are $5 \mathrm{~mL}$ and $10 \mathrm{~mL}$.

\section{B. MATERIALS AND TOOLS}

The experiment used the original mechanical system of the syringe pump brand B Braun type Compact. This mechanical system has functions to control the rate of the drug in the syringe and an optocoupler sensor to monitor the number of rotations of the stepper motor. Other components used include the Atmega16 microcontroller module, a motor driver to control the stepper motor, a $2 \times 16$ LCD to display the drug rate, and the amount of drug that has entered the patient. Additionally, the Nodemcu Esp8266 WiFi module was applied to indicate alarms in the form of notifications sent via smartphone, as shown in FIGURE 1.

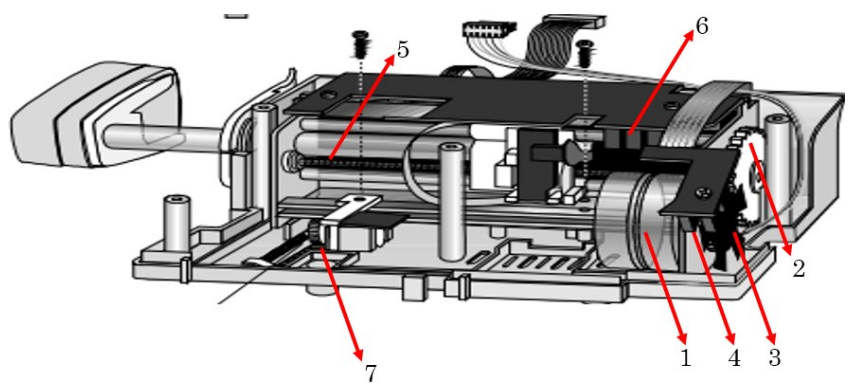

FIGURE 1. The mechanical system of the B Braun syringe pump [25]

The mechanical system of the syringe pump consists of several components that have synergistic functions.
According to the setting value, the stepper motor (1) rotates at speed. Gear (2) serves to convert the rotation of the motor into linear motion on the Feed screw (5). Then the motor's rotational speed is monitored by the sensor disk (3). The forward thrust can be determined with the ratio of the syringe size detected by the potentiometer (7). This is where the volume that comes out can be seen. And finally, this tool is also equipped with a Nearly empty sensor (6) to determine the remaining drug in the syringe and a volume counter sensor (4).

\section{EXPERIMENT}

In this study, the volume counter sensor was tested with a $10 \mathrm{ml}$ measuring cup (Iwaki brand) with a tolerance of $\pm 0.1 \mathrm{ml}$. This measurement aims to determine the speed of the drug flow rate driven by a stepper motor. This test also seeks to determine the amount of drug in the syringe before the alarm and "nearly empty" notification is sent to the smartphone.

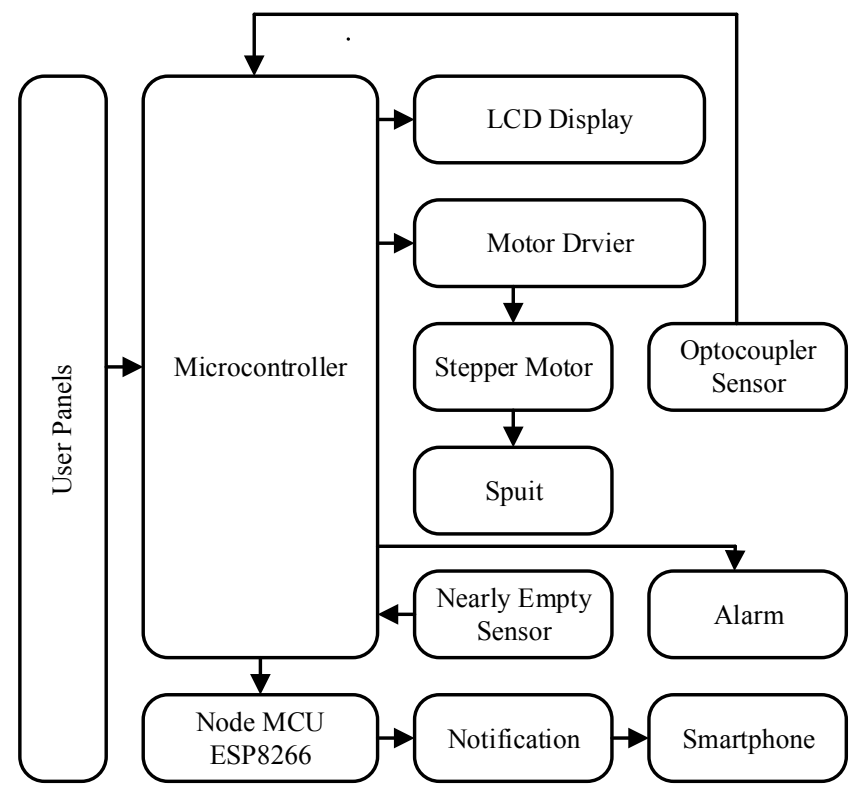

FIGURE 2. Block diagram of the experimental.

\section{BLOCK DIAGRAM}

When the device is turned on, the microcontroller waits for a command from the push button that is setting the drug flow rate. The push-button also gives an order to the microcontroller to start the drug delivery process. The stepper motor will drive the syringe at a speed according to the setting and controlled by the motor driver. The drug flow rate is censored by the volume counter sensor. The volume of drug that has been delivered in real-time will be displayed on the LCD screen. Nearly empty sensors will detect drugs that are running low so that an alarm sounds and a notification will be sent via smartphone to the user. The full block diagram block was shown in FIGURE 2. 


\section{RESULTS AND DISCUSSION}

In this study, testing was carried out using a $50 \mathrm{ml}$ syringe and a drug flow rate of $100 \mathrm{ml} /$ hour. The drug that has been delivered is seen on a measuring cup. Therefore, it can be compared with the volume monitored by the sensor.

\section{A. MODULE DESIGN}

The design of the module was shown in FIGURE 3 with the caption: 1. Microcontroller 2. Motor driver, 3. Buzzer/ Alarm, 4. Module WiFi Nodemcu ESP8266.

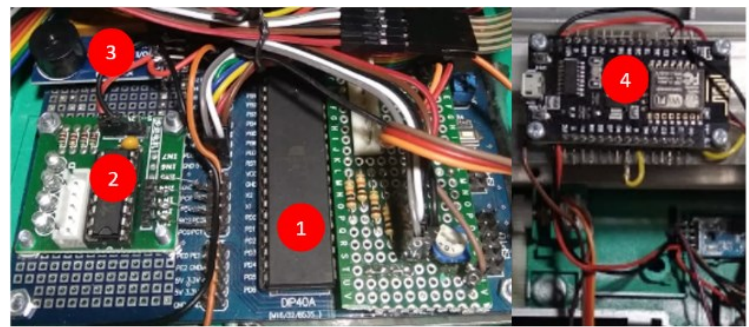

FIGURE 3. The module design of the device. (1) indicates microcontroller unit, (2) driver motor servo, (3) buzzer alarm, (4) Node MCU 8266.

\section{B. SYRINGE PUMP TEST RESULTS}

The accuracy of the dose produced by the syringe pump was tested using a measuring cup as shown in FIGURE 4 with a capacity of $10 \mathrm{~mL}$ and a tolerance of $\pm 0.1 \mathrm{~mL}$ with a target volume of $5 \mathrm{~mL}$ and $10 \mathrm{~mL}$. The test data are as shown in TABLE 1 and TABLE 2.

TABLE I

Testing of a syringe pump with a target volume of $5 \mathrm{ml}$

\begin{tabular}{ccccc}
\hline Testing & \multicolumn{2}{c}{ Measured Data } & $\begin{array}{c}\text { Time } \\
\text { (minute) }\end{array}$ & $\begin{array}{c}\text { Number } \\
\text { of sensor } \\
\text { readings }\end{array}$ \\
\cline { 2 - 3 } $\begin{array}{c}\text { Syringe } \\
\text { pump }(\mathrm{ml})\end{array}$ & $\begin{array}{c}\text { Measuring } \\
\text { cup }(\mathrm{ml})\end{array}$ & & 230 \\
2 & 4.990 & 5 & 3.000 & 232 \\
3 & 5.041 & 5 & 3.016 & 232 \\
4 & 5.041 & 5 & 3.018 & 231 \\
5 & 5.019 & 5 & 3.011 & 232 \\
6 & 5.041 & 5 & 3.015 & 232 \\
\hline Average & 5.041 & 5 & 3.016 & 231.5 \\
\hline
\end{tabular}

TABLE 2

Testing of a syringe pump with a target volume of $10 \mathrm{ml}$

\begin{tabular}{ccccc}
\hline Testing & \multicolumn{2}{c}{ Measured Data } & $\begin{array}{c}\text { Time } \\
\text { (minute) }\end{array}$ & $\begin{array}{c}\text { Number } \\
\text { of sensor } \\
\text { readings }\end{array}$ \\
\cline { 2 - 3 } & $\begin{array}{c}\text { Syringe } \\
\text { pump }(\mathrm{ml})\end{array}$ & $\begin{array}{c}\text { Measuring } \\
\text { cup }(\mathrm{ml})\end{array}$ & & 462 \\
2 & 10.039 & 10 & 6.013 & 463 \\
3 & 10.060 & 10 & 6.019 & 460 \\
4 & 9.995 & 10 & 6.000 & 460 \\
5 & 9.995 & 10 & 6.000 & 460 \\
6 & 9.995 & 10 & 6.010 & 460 \\
\hline Average & 9.995 & 10 & 6.000 & 460.8 \\
\hline
\end{tabular}

The test results in TABLE 1 showed that the volume of $5 \mathrm{~mL}$ in the measuring cup could be achieved in an average time of 3.012 minutes, while on the syringe pump is 5.03 minutes so the average volume in one minute is $1.669987 \mathrm{~mL}$. Thus the drug flow rate has a speed of $100.1 \mathrm{~mL} / \mathrm{h}$. The error rate of the amount of drug volume in the syringe pump compared to the measuring cup is $0.6 \%$, while the error rate of the drug rate compared to the setting is $0.1 \%$.

The test results in TABLE 2 showed that the volume of $10 \mathrm{~mL}$ in the measuring cup could be achieved in an average of 6.007 minutes, while the syringe pump is $10.013 \mathrm{~mL}$. Therefore, the average volume in one minute is 1.666889 $\mathrm{mL}$. Thus the drug rate has a speed of $100.01 \mathrm{~mL} / \mathrm{h}$. The error rate for the amount of drug volume in the syringe pump was compared with the measuring cup by $0.13 \%$, while the error rate for the drug rate was compared with the setting is $0.1 \%$.

Based on a $5 \mathrm{ml}$ measuring cup target, the drug rate in the syringe pump is $100 \mathrm{~mL} / \mathrm{h}$. The total volume is $5.041 \mathrm{~mL}$; based on Table 1 in the 5 th test, the volume counter sensor reads 232 data, so the sensor accuracy is $0.0217 \mathrm{~mL}$. Likewise, for the $10 \mathrm{ml}$ measuring cup target, based on table 2 of the $1 \mathrm{st}$ test, the total volume is $10.039 \mathrm{~mL}$ with a sensor reading of 462 , so the sensor accuracy is $0.0217 \mathrm{~mL}$.

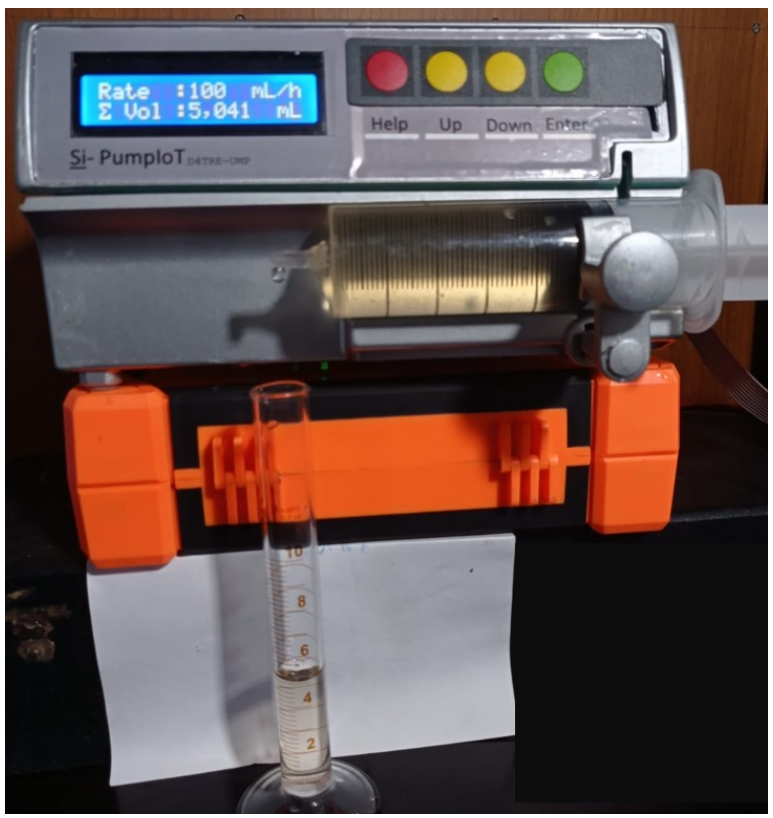

FIGURE 4. Testing the syringe pump with a measuring cup

\section{ALARM AND NOTIFICATION TESTING VIA SMARTPHONE}

In addition, testing the accuracy of the volume was carried out on alarm parameters and notifications via smartphones. A syringe pump equipped with a nearly empty sensor will detect the condition of the drug is almost empty. Nearly empty information will be displayed on the LCD screen on the syringe pump accompanied by a buzzer sound, as shown in FIGURE 5. Notifications are also sent to the smartphone, as shown in FIGURE 5(b). FIGURE 5(a) showed that nearly empty alarms and notifications occur when the medication amount is $10 \mathrm{~mL}$ left. At the same time, notifications are also sent via smartphone, as shown in FIGURE 5(b). Alarms and notifications always pop up every 30 seconds until there is 
an action from the user to reset the alarm, stop the drug or continue it.

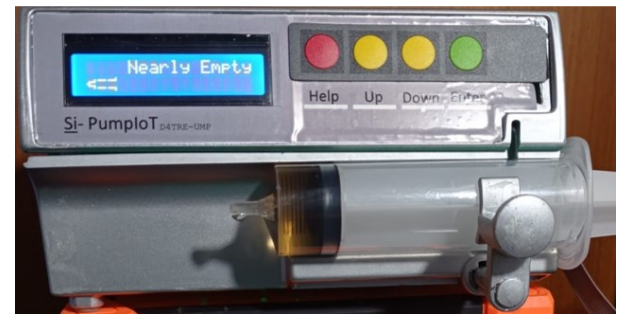

(a)

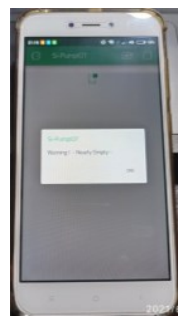

(b)
FIGURE 5. (a) Nearly empty alarms and notifications (b). Nearly empty notification sent to a smartphone.

The calculation of the average error at the target volume of $5 \mathrm{~mL}=0.6 \%$, while at the larger target of $10 \mathrm{~mL}=0.1 \%$. Errors can be caused by the accuracy of the measuring cup, which is read manually by the researcher. Based on Emergency Care Research Institute (ECRI) the requirement regarding the maximum permissible error in the syringe is $5 \%$ so that a syringe pump equipped with an IoT system is feasible to use. A nearly empty notification is sent via a smartphone when there is only $10 \mathrm{~mL}$ of medication remaining in a $50 \mathrm{~mL}$ syringe, different from using another syringe size. This is due to the use of an optocoupler sensor oriented to distance, not the diameter of the syringe.

Compared to previous research conducted by Miharja [1], they use a web-based application using the PHP programming language with the Mysql database. This study is more focused on dose calculation using a web application. After getting the data on the drug rate (cc/hour), it was entered manually into the syringe pump. In our study, it was more focused on patient safety. When the drug in the syringe pump is nearing empty, it will get a notification in the form of an alarm to the smartphone via IoT. This is due to the limited hearing distance of the alarm sound. Following the syringe pump standard, the drug rate data setting (cc/hour) is not changed.

The only limitation or weakness in this research is the limited use of a syringe pump on the device. This smart syringe pump can only detect 30 and $60 \mathrm{ml}$ syringe pump sizes. The limitation will be overcome by testing all types of syringe pump sizes in the future.

\section{CONCLUSION}

A smart syringe pump-based IoT was successfully designed using NodeMCU8266 WiFi. It can notify the smartphone and alarm that the liquid is nearly empty $(20 \%$ liquid or $10 \mathrm{~mL}$ of drug left in a $50 \mathrm{~mL}$ syringe). Furthermore, the volume counter sensor can read every $0.0217 \mathrm{~mL}$ with an average error of $0.6 \%$ at a volume of $5 \mathrm{~mL}$. While at the target volume of $10 \mathrm{~mL}$, the average error rate is $0.1 \%$. The findings are expected to be applied in the medical world to increase patient safety.

\section{REFERENCES}

[1] W. S. Kim, W. S. Lee, and Y. J. Kim, "A Review of the Applications of the Internet of Things (IoT) for Agricultural Automation," $J$. Biosyst. Eng., vol. 45, no. 4, pp. 385-400, 2020, doi: 10.1007/s42853020-00078-3.

[2] R. Gómez-Chabla, K. Real-Avilés, C. Morán, P. Grijalva, and T. Recalde, "IoT Applications in Agriculture: A Systematic Literature Review," Adv. Intell. Syst. Comput., vol. 901, pp. 68-76, 2019, doi: 10.1007/978-3-030-10728-4 8.

[3] R. K. Saini and C. Prakash, "Internet of Things (IoT) for Agriculture Growth using Wireless Sensor Networks," Glob. J. Comput. Sci. Technol., vol. 20, no. 2, 2020.

[4] E. Y. T. Adesta, D. Agusman, and Avicenna, "Internet of things (IoT) in agriculture industries," Indones. J. Electr. Eng. Informatics, vol. 5 , no. 4, pp. 376-382, 2017, doi: 10.11591/ijeei.v5i4.373.

[5] A. Mayub, Fahmizal, M. Shidiq, U. Y. Oktiawati, and N. R. Rosyid, "Implementation smart home using internet of things," Telkomnika (Telecommunication Comput. Electron. Control., vol. 17, no. 6, pp. 3126-3136, 2019, doi: 10.12928/TELKOMNIKA.v17i6.11722.

[6] T. A. Abdulrahman, O. H. Isiwekpeni, N. T. Surajudeen-Bakinde, and A. O. Otuoze, "Design, Specification and Implementation of a Distributed Home Automation System," Procedia Comput. Sci., vol. 94, no. IoTNAT, pp. 473-478, 2016, doi: 10.1016/j.procs.2016.08.073.

[7] M. P.N.V.S.N, S. T. Rao, and G. M. Rao, "Home Automation using Telegram," Ijarcce, vol. 6, no. 6, pp. 64-69, 2017, doi: 10.17148/ijarcce.2017.6613.

[8] S. Saha, R. H. Rajib, and S. Kabir, "IoT Based Automated Fish Farm Aquaculture Monitoring System," 2018 Int. Conf. Innov. Sci. Eng. Technol. ICISET 2018, no. October, pp. 201-206, 2018, doi: 10.1109/ICISET.2018.8745543.

[9] S. Karim, I. Hussain, A. Hussain, K. Hassan, and S. Iqbal, "IoT Based Smart Fish Farming Aquaculture Monitoring System," Int. J. Emerg. Technol., vol. 12, no. 2, pp. 45-53, 2021, [Online]. Available: www.researchtrend.net.

[10] K. Meethongjan and S. Kongsong, "Aquarium Fish Smart Farming on Internet of Things (IoT) and Mobile Application Technology," Int. J. Bus. Tour. Appl. Sci., pp. 22-28, 2019.

[11] A. P. J. P. J. Santoso, S. Luthfiyah, T. B. Indrato, and M. Omoogun, "Vital Sign Monitor Device Equipped with a Telegram Notifications Based on Internet of Thing Platform," Indones. J. Electron. Electromed. Eng. Med. informatics, vol. 3, no. 3, pp. 108-113, 2021, doi: 10.35882/ijeeemi.v3i3.4.

[12] J. Gómez, B. Oviedo, and E. Zhuma, "Patient Monitoring System Based on Internet of Things," Procedia Comput. Sci., vol. 83, no. Ant, pp. 90-97, 2016, doi: 10.1016/j.procs.2016.04.103.

[13] C. Li, X. Hu, and L. Zhang, "The IoT-based heart disease monitoring system for pervasive healthcare service," Procedia Comput. Sci., vol. 112, pp. 2328-2334, 2017, doi: 10.1016/j.procs.2017.08.265.

[14] A. M. Ghosh, D. Halder, and S. K. A. Hossain, "Remote health monitoring system through IoT," 2016 5th Int. Conf. Informatics, Electron. Vision, ICIEV 2016, pp. 921-926, 2016, doi: 10.1109/ICIEV.2016.7760135.

[15] S. Gupta, S. Kashaundhan, and D. C. Pandaey, "IoT-Based Patien Health Monitoring System," Lect. Notes Electr. Eng., vol. 471, pp. 177-183, 2018, doi: 10.1007/978-981-10-7329-8 18.

[16] L. E. Putri, Muhammad Ridha Mak'ruf, and Abd. Kholiq, "Syringe Pump With Nearly Empty Based Microcontroller Atmega328," J. Electron. Electromed. Eng. Med. Informatics, vol. 1, no. 2, pp. 25-30, 2019, doi: 10.35882/jeeemi.v1i2.5.

[17] B. Jung et al., "Efficacy evaluation of syringe pump developed for continuous drug infusion," J. Dent. Anesth. Pain Med., vol. 16, no. 4 p. 303, 2016, doi: 10.17245/jdapm.2016.16.4.303.

[18] K.-S. Seo and K. Lee, "Smart syringe pumps for drug infusion during dental intravenous sedation," J. Dent. Anesth. Pain Med., vol. 16, no. 3, p. 165, 2016, doi: 10.17245/jdapm.2016.16.3.165.

[19] K. S. Tee, M. S. Saripan, H. Y. Yap, and C. F. Soon, "Development of a Mechatronic Syringe Pump to Control Fluid Flow in a Microfluidic 
Device Based on Polyimide Film," IOP Conf. Ser. Mater. Sci. Eng., vol. 226, no. 1, 2017, doi: 10.1088/1757-899X/226/1/012031.

[20] E. D. Kurniawan, A. Adam, M. I. Salik, and P. L. Gareso, "Programmable Syringe Pump for Selective Micro Droplet Deposition," J. Elektron. dan Telekomun., vol. 19, no. 2, p. 75, 2019, doi: 10.14203/jet.v19.75-82.

[21] A. K. Patel et al., "Design and fabrication of infusion pump to control the flow rate of solution for synthesis of zinc oxide nanomaterial," Int. J. Appl. Eng. Res., vol. 14, no. 5, pp. 1091-1097, 2019.

[22] Mahmut UN, "Control System Design of Syringe Infusion Pump and MATLAB Simulations," Int. J. Sci. Res., vol. 7, no. 7, p. 6, 2018, doi: 10.21275/ART20183120.

[23] Aa. Silva and G. by Muhammadu Sathik Raja, "Advanced Control System For Syringe \& Infusion Pump Using IoT," Int. J. Innov. Res. Adv. Eng., vol. 6, no. 03, pp. 2349-2163, 2019, [Online]. Available: www.ijirae.com.

[24] Ascor, "Operating Manual Syringe Pump," 2007, [Online]. Available: http://www.ascor.com.pl/eng/pdf/ap14_om123_071123_gb.pdf.

[25] Batista, Elsa, Nelson Almeida, Eduarda Filipe, and Anselmo Costa. "Calibration and use of syringe pumps." In 16th International Congress of Metrology, p. 02007. EDP Sciences, 2013. 